\title{
Produção de conhecimento científico e tecnológico nos Institutos Federais de Educação, Ciência e Tecnologia: uma investigação sobre a sua natureza e aplicação $^{1}$
}

\section{Valmira Perucchi}

\begin{abstract}
Bibliotecária do Instituto Federal de Educação, Ciência e Tecnologia da Paraíba. Doutora em Ciência da Informação pela Universidade de Brasília (UnB)
\end{abstract}

Suzana Pinheiro Machado Mueller

Professora Colaboradora do Programa de PósGraduação em Ciência da Informação da Universidade de Brasília (UnB). PhD, Information Studies

http://dx.doi.org/10.1590/1981-5344/2503

Este artigo tem um objetivo duplo: primeiro, pretende identificar a posição dos professores dos Institutos Federais de Educação, Ciência e Tecnologia acerca da controvérsia entre o modelo linear de pesquisa, atribuído a Bush (1945), e o modelo representado por Stokes (2005). Segundo, verifica qual dentre os modelos sobre a relação empresa-universidade-governo, formulados por Sábato e Botana (2011), Lundvall (1992), Nelson e Rosenberg (1993), Leydesdorff e Etzkowitz (1996) e Etzkowitz e Leydesdorff (2000), melhor se adapta aos Institutos. $O$ universo da pesquisa são os 24.335 professores lotados nos 38 Institutos Federais existentes no país. Desse grupo, foi retirada uma amostra de 165 indivíduos, distribuída proporcionalmente ao número de professores de cada Instituto. Primeiramente, foi realizado levantamento dos dados desses 165 professores nos currículos registrados na Plataforma Lattes. Verificouse que 96 tinham seus currículos atualizados e com produção cadastrada. Para esses, foi enviado o questionário. Os dados obtidos foram submetidos às análises qualitativa e quantitativa. De acordo com os

\footnotetext{
${ }^{1}$ Este artigo é um desdobramento da tese Produção de conhecimento científico e tecnológico nos Institutos Federais de Educação, Ciência e Tecnologia: uma investigação sobre a sua natureza, divulgação e aplicação.
} 
resultados obtidos, concluímos que os professores/pesquisadores desenvolvem pesquisa básica e pesquisa aplicada de forma integrada, não se conformando, portanto, ao modelo linear de pesquisa de Bush, aproximando-se do modelo proposto por Stokes. Quanto aos modelos empresa-universidade-governo, 0 que parece melhor se adaptar à realidade dos Institutos Federais é o Triângulo de Sábato, que atribui ao Governo o papel de principal incentivador.

Palavras-chave: Institutos Federais de Educação; Ciência e Tecnologia; Modelo linear de pesquisa; Quadrante de Pasteur; Modelos de relação empresauniversidade-governo.

\section{Production of scientific and technological knowledge in the Federal Institutes of Education, Science and Technology: an investigation about its nature and use}

This article has a twofold objective: first, it aims at identifying the position held by Brazilian Federal Institutes of Education, Science and Technology professors on the controversy between the linear model of research, attributed to Bush (1945), and the model proposed by Stokes (2005). Second, it attempts at verifying which of the three models proposed to describe enterpriseuniversity-government relations, as formulated by Sábato and Botana (2011), Lundvall (1992), Nelson and Rosenberg (1993), Leydesdorff and Etzkowitz (1996) and Etzkowitz and Leydesdorff (2000), suits better the Institutes. The research universe consists of 24,335 professors from 38 Federal Institutes in existence in the country, from which a sample of 165 individuals was withdrawn and distributed proportionally to the number of professors in each Institute. Firstly, a survey of the curricula of the 165 professors was conducted in the Lattes Platform. It was verified that 96 professors had their curricula updated and had production registered. For these professors, a questionnaire was sent. The obtained data were submitted to qualitative and quantitative analyses. According to the obtained results, we concluded 
that the professors/researchers carry out basic research and applied research in an integrated way, thus not conforming to Bush's linear model, but being closer to the model proposed by Stokes. Regarding the enterpriseuniversity-government relations models, Sabato's Triangle, attributing to the government the role of the main stimulator, seems to describe better the reality of the Federal Institutes.

Keywords: Federal Institutes of Education; Science and Technology; Research linear model; Pasteur's quadrant; Industry-university-government relation models.

Recebido em 10.08.2015 Aceito em 29.12.2015

\section{Introdução}

Os Institutos Federais de Educação, Ciência e Tecnologia (Institutos Federais) foram criados pela Lei 11.892 em 29 de dezembro de 2008 a partir da transformação e/ou integração das antigas Escolas Agrotécnicas Federais, Escolas Técnicas e dos Centros Federais de Educação Tecnológica (CEFETs) (BRASIL. Presidência da República, 2008). Essa Lei parece atestar a crença de seus fundadores nas ideias de Bush (1945), já que atribui a responsabilidade da produção do conhecimento científico e tecnológico às instituições diferentes, que são, respectivamente, as Universidades e os Institutos Federais.

Existe na literatura uma discussão sobre o que seria mais adequado ao desenvolvimento da ciência, se a produção em separado ou integrada do conhecimento científico (ciência pura) e tecnologia (ciência aplicada). Essa discussão é conhecida como o pensamento tradicional e o pensamento atual. O primeiro, representado pelas ideias de Bush (1945), defende que a pesquisa básica não deve objetivar resolver problemas, mas sim entendê-los, e, portanto, pesquisa básica e pesquisa aplicada deveriam ser desenvolvidas separadamente, aquela precedendo esta, e por cientistas diferentes. O chamado pensamento atual é baseado nas ideias de Stokes (2005), que defende que há várias formas de produzir conhecimento, entre elas a pesquisa básica, a pesquisa aplicada, e ainda as duas formas de maneira conjunta. $O$ pensamento atual também não aceita ser a pesquisa básica a fonte de toda a tecnologia, reconhecendo que é possível também a tecnologia preceder a pesquisa básica.

A produção do conhecimento nas sociedades modernas envolve instituições de ensino e pesquisa, empresas e governo. As instituições de ensino devem criar. Consequentemente, as empresas aplicariam o que foi criado nas instituições de ensino, e o governo estimula a criação nas instituições de ensino e a aplicação nas empresas por meio de políticas, legislações e financiamentos. Os modelos que representam as relações 
entre universidade-empresas-governo nas atividades referentes à produção de conhecimentos científicos e tecnológicos tentam atribuir a função de cada integrante no processo do conhecimento, reconhecendo também sua inter-relação. Nas teorias das relações universidadesempresas-governo, e para fins desta pesquisa, os Institutos Federais são equiparados às universidades, pois realizam o papel de instituições de ensino como as universidades nessas relações.

Segundo a Lei 11.892 (BRASIL. Presidência da República, 2008), os Institutos Federais devem desenvolver pesquisa aplicada em articulação com os diversos setores da economia, com ênfase no desenvolvimento socioeconômico local, regional e nacional, implementando, assim, as relações com o governo e as empresas. Diante do exposto, e tendo como referência as divergências entre Bush (1945) e Stokes (2005), e ainda, os diferentes modelos de relação entre universidade-empresa-governo (ETZKOWITZ; LEYDESDORFF, 2000; LEYDESDORFF; ETZKOWITZ, 1996; LUNDVALL, 1992; NELSON; ROSENBERG, 1993; SÁBATO; BOTANA, 2011), esta pesquisa pretende responder às seguintes perguntas: como os professores/pesquisadores dos Institutos Federais caracterizam suas pesquisas em relação ao modelo linear da ciência e da tecnologia?; como esses professores/pesquisadores descrevem a relação entre seu Instituto Federal, as empresas e o governo? O objetivo é perceber, a partir das respostas obtidas, se os professores/pesquisadores dos Institutos Federais refletem, em suas ideias e práticas, o modelo linear de pesquisa que parece ter inspirado a Lei que criou os Institutos e também verificar como percebem a atuação das empresas e governo em suas atividades.

A pesquisa pretende contribuir para um melhor entendimento da atuação dos Institutos Federais e também oferecer à comunidade em geral informações sobre como vêm sendo desenvolvidas as atividades de pesquisa nessas Instituições, especialmente com relação à aplicação do que foi produzido. O tema é também relevante para a área de Ciência da Informação, especialmente nos estudos de produção do conhecimento científico e tecnológico.

\section{Modelos de produção do conhecimento em ciência e tecnologia e inovação}

Vários modelos que representam as interações entre ciência e tecnologia têm sido propostos. Para este estudo, nós abordaremos três.

O primeiro modelo traz as ideias de Bush divulgadas através da publicação de seu relatório ao Presidente Roosevelt, em 1945, Science, the endless frontier. A essência do modelo linear, defendido por Bush (1945), é a diferença entre os objetivos da pesquisa básica e da pesquisa aplicada. Afirma que o avanço da ciência se dá por meio do melhor entendimento da natureza, e que as pesquisas devem ter apenas esse objetivo. A solução de problemas da sociedade seria buscada por outro tipo de pesquisador, que trabalharia com base nos avanços da ciência realizados pelos cientistas puros. 
O segundo foi proposto por Gibbons et al. em 1994, em um estudo abrangente intitulado The new production of knowledge: the dynamics of science and research in contemporary societies ${ }^{2}$ e ficou conhecido como Modo 2 de produção do conhecimento. A essência do modelo proposto por Gibbons (2001) é a existência de dois modos de produção de conhecimento. O Modo 1 é o modo tradicional, desenvolvido nas academias e institutos de pesquisa, com divulgação em periódicos referendados. O Modo 2 é a descoberta de mais conhecimento por meio da solução de problemas que ocorrem na vida real, nas indústrias e sociedade em geral, mas fora da academia. Reúne diferentes tipos de cientistas e profissionais de vários campos, conforme o problema a ser resolvido. A equipe se forma e se dissolve após a solução de problemas. A validação do conhecimento não se dá pela publicação em revista referendada (embora isso possa ocorrer), mas pela solução do problema.

O terceiro foi apresentado por Stokes (2005) em seu livro $O$ Quadrante de Pasteur em 1997. Nesse livro, Stokes contesta o modelo que percebe a pesquisa básica e a pesquisa aplicada como sendo atividades que devem ser realizadas por diferentes pesquisadores e cujos objetivos devem ser mantidos separados; aquela visando ao entendimento da natureza e avanço do conhecimento científico, e esta visando à solução de problemas práticos, baseada nos resultados obtidos pela primeira. Defende, ao contrário, a possibilidade de várias formas de conduzir pesquisas científicas, inclusive aquela voltada ao mesmo tempo para o entendimento e solução de problemas.

A essência da proposta de Stokes (2005) é a coexistência de vários tipos de pesquisa e a aceitação de vários tipos de pesquisadores engajados nessas pesquisas. Stokes (2005) propõe uma visão reformulada entre entendimento e uso como objetivos da pesquisa e entre as categorias de pesquisa básica (entendimento) e pesquisa aplicada (uso) como demonstra o quadrilátero com as quatro câmaras. Esse quadrilátero é representado pela: célula superior à esquerda chamada de quadrante de Bohr, que é a pesquisa básica pura; o canto superior direito chamado de quadrante de Pasteur é a pesquisa básica inspirada pelo uso; o quadrante inferior à esquerda, que não está vazio, inclui todas as pesquisas que exploram sistematicamente fenômenos particulares, sem ter em vista o entendimento e o uso; e a célula no canto direito inferior, chamada de quadrante de Edison, é a pesquisa aplicada pura.

Os três modelos influenciam a forma como são produzidas a ciência, tecnologia e inovação em diversos países. No Brasil, com a existência das universidades e dos Institutos Federais parece prevalecer o modelo de Bush (1945), para quem a ciência, tecnologia e inovação são produzidas separadamente.

\footnotetext{
2 Para esta revisão, utilizaremos o artigo de Gibbons (2001) Innovation and the developing system of knowledge production que traz resumidamente o conteúdo do Modo 2.
} 


\section{Teorias da relação universidade-empresas-governo}

Existem na literatura estudos teóricos que descrevem as relações entre universidade-empresa-governo. As principais teorias são: Triângulo de Sábato, Sistemas Nacionais de Inovação e a Tripla Hélice. Apesar de as três teorias apresentarem a relação entre universidade-empresa-governo, há diferenças entre elas.

O Triângulo de Sábato tem como ator principal o Governo (Estado) no processo de desenvolvimento científico e tecnológico. O Triângulo de Sábato e Botana (2011) é um modelo de política científica e tecnológica para orientar como e onde inovar. Essa teoria reconhece que para existir uma estrutura científica e tecnológica produtiva são necessários três elementos que devem interagir de forma permanente: a universidade (cria), a empresa (aplica) e o governo (estimula). Esses elementos representam um triângulo em que os vértices se relacionam entre si com o objetivo de gerar, incorporar e transformar demandas em um produto final que é a inovação científica e tecnológica.

O modelo conhecido como Sistemas Nacionais de Inovação apontam a empresa como tendo papel principal no processo de inovação. Os sistemas nacionais de inovação apareceram no final da década de 80 e início dos anos 90 com Lundvall (1992) e Nelson e Rosenberg (1993). Esses autores destacam a empresa como a maior responsável pelo processo de inovação por compartilharem a ideia de que cientistas não procuram aplicações úteis nas suas investigações, sendo esse papel desempenhado pelas empresas. Nos sistemas nacionais de inovação, Lundvall (1992) e Nelson e Rosenberg (1993) veem a empresa como a maior responsável pela inovação. Entretanto, existe uma diferença de opinião entre esses autores: Lundvall destaca o papel do Estado no processo de inovação, e Nelson e Rosenberg ressaltam o papel das universidades.

O modelo da Tripla Hélice considera que a universidade desempenha papel mais relevante no processo. A Tripla Hélice aborda a relação entre universidade, indústria e governo na geração de conhecimento e inovação. De acordo com essa teoria, a relação faria com que o conhecimento produzido chegasse ao ambiente produtivo com maior rapidez e eficácia. Desenvolvida a partir de meados da década de 1990, a tripla hélice nas relações universidade-indústria-governo é discutida por Leydesdorff e Etzkowitz (1996) e Etzkowitz e Leydesdorff (2000) com foco no futuro da pesquisa universitária, no regime emergente de produção e divulgação de conhecimento. Leydesdorff e Etzkowitz (1996, p. 279-280) propõem modelar o sistema como uma tripla hélice das relações universidadeindústria-governo em que "três dinâmicas podem ser distinguidas: a dinâmica econômica do mercado, a dinâmica interna de produção de conhecimento, e de governança da interface em diferentes níveis".

As teorias das relações entre universidade-empresa-governo privilegiam, cada uma, a ação de um dos três atores (universidadeempresa-governo) no desenvolvimento da ciência, tecnologia e inovação 
em praticamente todos os países. O governo tem o papel de estimular a estrutura produtiva com a formulação de políticas e com a mobilização de recursos; a indústria aplica produzindo bens e serviços; e a universidade cria através do desenvolvimento de pesquisas aquilo que deverá ser produzido. No Brasil, o governo articula e estimula as relações entre universidade-empresa-governo, o que sugere que em nosso país parece prevalecer o Triângulo de Sábato cujo governo é o maior incentivador da produção de ciência, tecnologia e inovação.

\section{Procedimentos metodológicos}

Tendo em vista as perguntas de pesquisa e o objetivo, esta pesquisa iniciou-se com a busca dos dados dos professores dos Institutos Federias nos currículos da Plataforma Lattes e, posteriormente, foi complementada com entrevistas com os professores/pesquisadores dos Institutos Federais.

O universo da pesquisa são os professores dos 38 Institutos Federais. O número de professores e a lista com os seus nomes foram obtidos com a Coordenação Geral de Desenvolvimento de Pessoas da Rede Federal de Educação Profissional, Científica e Tecnológica. O pedido foi registrado no Sistema Eletrônico do Serviço de Informações ao Cidadão (e-SIC). A quantidade e a lista com os nomes dos professores dos 38 Institutos Federais foram disponibilizadas no e-SIC em 9 de dezembro de 2013. Constavam nesta data 24.335 professores efetivos (em regime de trabalho de 20 horas, 40 horas e dedicação exclusiva) distribuídos pelos 38 Institutos Federais. Os professores efetivos que ingressaram posteriormente a esta data não serão incluídos nesta pesquisa.

Dada a quantidade de professores nos 38 Institutos Federais, 24.335, foi necessário calcular uma amostra sobre a qual realizar a busca dos dados nos currículos da Plataforma Lattes. O tipo de amostra mais adequado para a presente pesquisa é a amostra aleatória simples. O resultado apontou para 165 professores que foram distribuídos proporcionalmente pela quantidade de professores em cada Instituto Federal. Para as entrevistas, foram escolhidos os 96 professores/pesquisadores dos Institutos Federais da amostra da pesquisa inicialmente realizada que tinham seus currículos atualizados e com produção cadastrada.

O contato inicial com os professores/pesquisadores dos Institutos Federais aconteceu por e-mail, e teve como finalidade saber sobre a disponibilidade de responder ao questionário. Foram elaboradas questões fechadas e abertas. Os roteiros de entrevista foram enviados por e-mail. Os respondentes das entrevistas não foram identificados pelo seu nome para garantir o seu anonimato, mas foram identificados por siglas; por exemplo, IFBA1 para o professor do Instituto Federal da Bahia e assim sucessivamente para os casos em que haja mais de um professor por instituto. 
Para a coleta dos dados, foram enviadas cinco remessas sucessivas de e-mails para os professores/pesquisadores dos Institutos Federais. A primeira foi na segunda quinzena de setembro de 2014. Após o envio dessa remessa, esperamos quinze dias e enviamos a segunda remessa. Mais quinze dias e enviamos a terceira remessa. Até a terceira remessa, obtivemos algumas respostas aos e-mails com os questionários respondidos. As duas últimas remessas foram enviadas com intervalo de uma semana, até porque na quarta remessa de envio de e-mails para os professores/pesquisadores já não obtivemos nenhuma resposta e nem questionários respondidos. Assim, a coleta dos dados das entrevistas foi finalizada na primeira semana de novembro de 2014.

Das 96 entrevistas enviadas, obtivemos como resposta: professores/pesquisadores que responderam ao questionário $67,71 \%$ (65); professores/pesquisadores que não responderam 30,21\% (29) e professores/pesquisadores que justificaram não ter interesse em participar da pesquisa $2,08 \%(2)$.

Os dados coletados foram transcritos para planilhas no Excel. Os dados são analisados quantitativamente e qualitativamente.

\section{Análise dos resultados da pesquisa}

A seguir, apresentamos os resultados do levantamento e das análises dos dados obtidos, aqui organizados em duas seções: dados relacionados ao tipo de pesquisa desenvolvida pelos professores/pesquisadores dos Institutos Federais, e dados relacionados à relação entre Institutos Federais-empresas-governo.

\subsection{Tipo de pesquisa}

Apresentamos os resultados relacionados ao objetivo de identificar o tipo de pesquisa desenvolvida pelos professores/pesquisadores dos Institutos Federais, em ciência e tecnologia em separado ou simultaneamente, levantado pela questão cujo enunciado foi o seguinte: existe uma corrente que separa totalmente a pesquisa básica (que visa prioritariamente ao entendimento) da pesquisa aplicada (que visa prioritariamente ao uso). Outra corrente diz que a pesquisa básica e a pesquisa aplicada se complementam e existem casos que são feitas pela mesma pessoa. Qual a opinião do(a) senhor(a) com relação a esses tipos de pesquisa: entendimento e uso?

A pergunta visava ao entendimento do conceito, mas os professores/pesquisadores responderam com o que fazem. Houve uma variedade de respostas, dos professores/pesquisadores dos Institutos Federais, que foi agrupada conforme o pensamento de Bush (1945) para quem a pesquisa básica e a pesquisa aplicada são desenvolvidas em separado, e Stokes (2005) para quem existe uma integração entre a pesquisa básica e a pesquisa aplicada. Para os 65 professores/pesquisadores dos Institutos Federais que responderam ao 
questionário, as pesquisas desenvolvidas são: pesquisa básica e pesquisa aplicada desenvolvidas de forma integrada 55,39\% (36); pesquisa básica e pesquisa aplicada desenvolvidas em separado 33,85\% (22); e não responderam 10,76\% (7). De acordo com a opinião dos professores/pesquisadores dos Institutos Federais, o tipo de pesquisa que parece ser a mais desenvolvida é aquele em que a pesquisa básica e a pesquisa aplicada se complementam, ou seja, são desenvolvidas simultaneamente podendo ou não ser realizadas pela mesma pessoa.

As opiniões dos professores/pesquisadores dos Institutos Federais sobre o tipo de pesquisa que desenvolvem permitiram que fossem comparadas aos tipos representados no quadrilátero de quatro câmeras, representado pela Figura 1.

Figura 1 - Modelo de quadrantes de pesquisa científica

Considerações de uso?

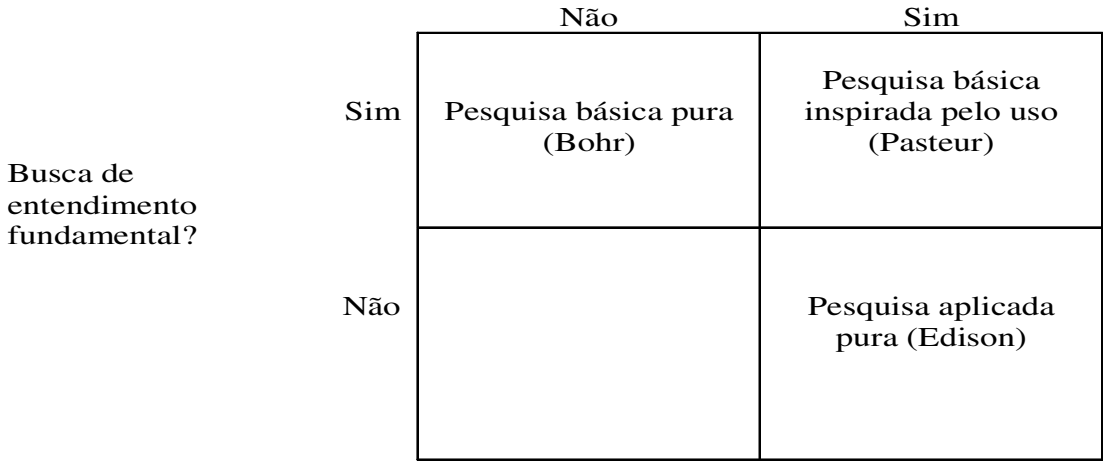

Fonte: STOKES (2005, p. 118).

Resultados mostram que as pesquisas desenvolvidas pelos professores/pesquisadores são semelhantes ao tipo de pesquisa representado no Quadrante de Pasteur (canto superior direito), no qual a pesquisa básica e a pesquisa aplicada são resultantes de uma mesma pesquisa, ou seja, são desenvolvidas de forma integrada. As pesquisas desenvolvidas no Quadrante de Pasteur contribuem para o avanço do conhecimento ao mesmo tempo em que têm aplicações práticas. Stokes (2005) defende que tanto a ciência inspira e precede a tecnologia quanto a tecnologia inspira e motiva a descoberta científica. Entretanto, a Lei que cria os Institutos Federais (BRASIL. Presidência da República, 2008) parece ter sido inspirada pelo modelo linear de Bush (1945), que privilegia o desenvolvimento da pesquisa aplicada separada da pesquisa pura.

Constam, a seguir, separadas pelos tipos de pesquisa que os professores/pesquisadores desenvolvem nos Institutos Federais, as transcrições das respostas consideradas mais relevantes:

1) favorecendo a pesquisa básica: 
Atualmente só possuímos cursos de nível integrado e trabalhos com a pesquisa básica. (Professor/pesquisador do IFPR4).

Desenvolvo pesquisa que visa 0 entendimento. (Professor/pesquisador do IFBA6).

Minhas pesquisas não têm resultado prático, são de entendimento. (Professor/pesquisador do IFAC2).

2) favorecendo a pesquisa aplicada:

Na minha área, tecnologia, as pesquisas tendem ao USO. (Professor/pesquisador do IFPB5).

Acredito que as pesquisas nos Institutos Federais devem ser voltadas para uso. (Professor/pesquisador do IFS3).

A pesquisa pela pesquisa é o expediente muito utilizado pelas Universidades, utilizando as palavras do então Secretário Eliezer Pacheco: 'Os Institutos não são e nunca serão uma Universidade', esse comentário nos leva a crer que a pesquisa dos Institutos deve ser aplicada e em muito ele está certo, pois o local da ciência pela ciência é a Universidade. (Professor/pesquisador do IFFARROUPILHA1).

3) favorecendo a pesquisa básica e pesquisa aplicada conjuntamente:

Considero minhas pesquisas como de entendimento e uso conjuntamente. (Professor/pesquisador do IFC2).

Sou da opinião que a pesquisa básica e a pesquisa aplicada se complementam e eu sempre pesquisei com esse entendimento. (Professor/pesquisador do IFSUDESTEMG1).

Eu acredito que a pesquisa básica e pesquisa aplicada são complementares, pois uma prescinde da outra para 0 desenvolvimento da ciência e inovação. (Professor/pesquisador do IFAM3). 
Entendo que a pesquisa básica e a aplicada podem sim caminhar juntas e, muitas vezes, serem complementares uma à outra, podendo ou não ser feitas pela mesma pessoa. (Professor/pesquisador do IFMT5).

Penso que apesar desses dois tipos terem objetivos específicos, ambas podem se complementar. No entanto, vejo que os INSTITUTOS se aproximam e diferenciam pela pesquisa aplicada, com forte viés de inovação tecnológica. (Professor/pesquisador do IFPE5).

Compreendo que o conhecimento básico não seja produzido antes de sua aplicação, mas sim no próprio contexto da aplicação. Dessa maneira, é possível trabalhar com a hipótese de que não exista barreira sólida entre pesquisa básica e aplicada e que, de algum modo, esses dois vieses científicos podem estar fundidos. Mesmo assim, compreendo que exista e respeito a postura de quem compreende os dois tipos de pesquisa separadamente. Nos Institutos Federais, há discussões que levam o modelo atual para o que se pode chamar de modelo de integração. A ideia de integração preconiza a integração entre diversos elementos, mas principalmente entre educação profissional e educação básica. Nesse movimento também se pode incluir a integração entre conhecimento básico e conhecimento aplicado. Compreendo que dessa maneira, pelo viés da integração, que devemos atuar nos Institutos Federais. (Professor/pesquisador do IFMS1).

Penso que toda pesquisa deveria levar em conta os dois aspectos. Não imagino pesquisa aplicada sem entendimento e vice-versa. Ambas se complementam e devem ser realizadas pela mesma pessoa. Infelizmente na Capes e SETEC o privilégio está sendo dado a pesquisas aplicadas, no seu sentido estreito, aplicável, pragmático. (Professor/pesquisador do IFTO1).

Acredito que as duas correntes devam caminhar juntas, na tentativa de unir ao máximo a pesquisa básica à sua aplicação prática, principalmente pensando no retorno financeiro de um alto investimento em pesquisa. Se a pesquisa básica permanecer totalmente desvinculada da pesquisa aplicada, corre-se o risco de fomentar o desenvolvimento de projetos que serão pouco divulgados entre a comunidade científica e servirão unicamente para o crescimento de números institucionais. (Professor/pesquisador do IFTM2). 
As transcrições acima refletem opiniões divergentes. Algumas estão de acordo com as ideias de Bush (1945), como atestam as opiniões de alguns professores de que os Institutos Federais apoiam "prioritariamente atividades de pesquisa que destacam claramente o uso em primeiro plano, ou seja, pesquisa de resultados concretos" Professor/pesquisador do IFCE4. No entanto, predominam aquelas que estão de acordo com as ideias de Stokes (2005).

Schwartzman (2002, p. 374) reforça o ponto de vista de Stokes ao afirmar que descrever o desenvolvimento de pesquisa como obedecendo a "uma sequência linear, que vai da pesquisa básica à pesquisa aplicada, desta ao desenvolvimento tecnológico, e deste, finalmente, ao produto de uso prático, não é a melhor descrição do que ocorre no mundo real." O autor complementa que "a geração de conhecimento e suas aplicações não ocorrem necessariamente em sequência, e as melhores instituições científicas são as que fazem bem as duas coisas." (SCHWARTZMAN, 2002, p. 19).

\subsection{Relação entre Instituto Federal-empresas-governo}

A seguir, apresentamos os resultados obtidos para contemplar o objetivo de identificar interações entre os Institutos Federais e empresas na condução de atividades de pesquisa.

Ao perguntarmos: o(a) senhor(a) tem conhecimento de parcerias nas atividades de pesquisas do seu Instituto Federal com empresas? Caso a resposta seja positiva, o(a) senhor(a) poderia dar um exemplo? Obtivemos as seguintes respostas: $61,54 \%$ (40) dos professores/pesquisadores não têm conhecimento de parcerias nas atividades de pesquisas do seu Instituto Federal com empresas, e 38,46\% (25) dos professores/pesquisadores têm conhecimento da existência de parcerias.

Com relação aos exemplos solicitados aos professores/pesquisadores no que concerne à relação entre Instituto Federal e empresas, foi obtida uma variedade de respostas: CAPES; CNPq; Sebrae; Fiocruz; Fundação de Amparo à Pesquisa do Estado de Goiás (Fapeg); Agência Estadual de Defesa Agropecuária da Bahia (Adab); Petrobras; Empresa Brasileira de pesquisa Agropecuária (EMBRAPA); Cooperativa da Agricultura Familiar Sustentável com base na Economia Solidária Ltda (Copabase); Centro de Informação e Assessoria Técnica (CIAAT); Secretaria de Vigilância Sanitária; Empresa de Pesquisa Agropecuária de Minas Gerais (EPAMIG); Centro Operacional de Desenvolvimento e Saneamento de Uberaba (CODAU); Empresa de Pesquisa Agropecuária e Extensão Rural de Santa Catarina (EPAGRI); universidades federais; associações da sociedade civil organizada; associações de bairros; organizações não governamentais; Fiat; Ford; Siemens; empresas de telefonia; Fábrica de briquetes; pequenos produtores rurais; multinacionais e empresas de telecomunicações. 
Esses exemplos apontam que os Institutos Federais mantêm relações mais estreitas com governo (empresas públicas) e pouco com as empresas privadas.

Além dos exemplos, destacamos a seguir algumas opiniões dos professores/pesquisadores em relação às parcerias dos Institutos Federais com as empresas:

1) existência de parcerias:

A instituição mantém parcerias com empresas do ramo agrícola (adubo, máquinas) e da agroindústria (panificadoras, frigoríficos, laticínios), onde são desenvolvidos ou testados novos produtos. (Professor/pesquisador do IFMT2).

Temos uma incubadora de economia solidária que mantém quatro empresas em estágio de incubação no momento. (Professor/pesquisador do IFMS1).

Ainda não tive chance de tirar proveito de nenhum desses vínculos. Em única oportunidade, a relação Instituto/Empresa foi toda desenvolvida informalmente pelo grupo de pesquisa (professor e alunos). (Professor/pesquisador do IFMA5).

Para os alunos fazerem as disciplinas obrigatórias do estágio tem que ter uma empresa onde possam atuar. Empresas privadas e públicas. (Professor/pesquisador do IFAM4).

2) inexistência de parcerias:

Não tenho conhecimento. Tenho minhas restrições quanto às pesquisas públicas atenderem demandas de empresas privadas. (Professor/pesquisador do IFG5).

No Instituto Federal Farroupilha por regra não estimula a parceria Público-Privada. (Professor/pesquisador do IFFARROUPILHA1).

O que pode ser observado é que a relação entre Institutos Federaisempresas-governo está mais para o Triângulo de Sábato do que para a tripla hélice ou os sistemas de inovação. Isso porque o ator principal nessa relação parece ser o governo e não os Institutos Federais ou as empresas. Corroborando esses resultados, Schwartzman (2002, p. 363) argumenta que o "grande comprador e usuário da pesquisa científica e 
tecnológica não é necessariamente o setor produtivo privado, mas o setor público." E diz que:

[...] são os governos que fazem guerras, produzem armamentos, respondem a emergências e catástrofes, cuidam da saúde pública, da educação, da ordem pública, do meio ambiente, do abastecimento de água, saneamento, energia, transportes públicos, comunicações, fazem mapeamentos e preveem o tempo. Todas estas atividades requerem pesquisas e estudos permanentes, e grandes investimentos (SCHWARTZMAN, 2002, p. 363).

A existência de estruturas internas com o objetivo de facilitar a transferência do conhecimento científico para o meio empresarial, mediante o desenvolvimento de pesquisas conjuntas entre os Institutos Federais e empresas é uma atividade que deve ser estimulada. Segundo Fujino (2006, p. 374), "a empresa é o instrumento necessário para transformar resultados de pesquisa em produtos e processos que permitam o atendimento das demandas da sociedade e o retorno do investimento público em pesquisa."

As relações entre os Institutos Federais e as empresas devem, segundo Querido (2011, p. 35-36), ser realizadas pelos núcleos de inovação tecnológica, pois estão habilitados para "realizar serviços em propriedade intelectual que incluem a realização da interface universidade-empresa, o apoio à elaboração de projetos para financiamento, a informação sobre incentivos fiscais, [...] dentre outras atividades."

A partir da Lei 10.973 (BRASIL. Presidência da República, 2004), os núcleos de inovação tecnológica foram criados para desenvolverem atividades referentes à inovação e à pesquisa científica e tecnológica. Dentre as atividades desempenhadas pelos núcleos de inovação tecnológica está a de formar parcerias com empresas e organizações de direito privado sem fins lucrativos, como consta na Lei:

Art. 30 A União, os Estados, o Distrito Federal, os Municípios e as respectivas agências de fomento poderão estimular e apoiar a constituição de alianças estratégicas e o desenvolvimento de projetos de cooperação envolvendo empresas nacionais, Instituição Científica e Tecnológica e organizações de direito privado sem fins lucrativos voltadas para atividades de pesquisa e desenvolvimento, que objetivem a geração de produtos e processos inovadores.

$[\ldots]$

Art. 19. A União, as Instituições Científicas e Tecnológicas e as agências de fomento promoverão e incentivarão 0 desenvolvimento de produtos e processos inovadores em empresas nacionais e nas entidades nacionais de direito 
privado sem fins lucrativos voltadas para atividades de pesquisa, mediante a concessão de recursos financeiros, humanos, materiais ou de infraestrutura, a serem ajustados em convênios ou contratos específicos, destinados a apoiar atividades de pesquisa e desenvolvimento, para atender às prioridades da política industrial e tecnológica nacional. (BRASIL. Presidência da República, 2004).

Para Schwartzman (2002, p. 362-363), existe a "necessidade de que as instituições de pesquisa não fiquem isoladas, e tratem de se vincular mais fortemente ao setor produtivo, tornando-se mais relevantes e conseguindo, ao mesmo tempo, mais apoio e recursos." O autor cita como exemplo que "nos países mais desenvolvidos, a integração entre as instituições científicas e tecnológicas e o sistema produtivo se dá de forma muito mais completa e natural do que nos países em desenvolvimento, onde o setor científico e tecnológico tenderia a ficar mais isolado." $E$ sugere que "isto deveria ser compensado por um esforço dirigido e sistemático para aproximar a pesquisa do setor produtivo, através de diferentes tipos de incentivos financeiros e inovações institucionais."

Schwartzman (2008, p. 20) lembra que "nas economias desenvolvidas, a maior parte da pesquisa e do desenvolvimento tecnológico ocorre em empresas privadas, bem como em instituições de pesquisa governamentais, civis e militares." Schwartzman cita que as "universidades de pesquisa são únicas em sua habilidade para atrair e educar pesquisadores qualificados e trabalhar na fronteira da pesquisa científica, e há uma tendência crescente das corporações privadas [de] desenvolverem parcerias estratégicas com universidades."

O desenvolvimento da pesquisa, segundo Schwartzman (2005, p. 5), se modificou em nosso país a partir dos anos 90. Essa mudança passou a estimular um vínculo com o setor produtivo. "A ideia é que, vivendo somente à custa de dinheiro público, a ciência tenderia a se burocratizar, não produzir resultados significativos, e acabaria não conseguindo recursos adicionais para continuar se desenvolvendo." Se a pesquisa científica desenvolvida "fizesse parte de um sistema de inovação mais amplo, que incluísse também o setor produtivo e empresarial, ela passaria a ser avaliada pelos seus resultados, se tornaria muito mais relevante, e teria muito mais facilidade de conseguir apoio." Essa forma de fazer ciência, de certa forma, "trata-se de uma volta à concepção utilitarista da ciência que vem dos positivistas de 100 anos atrás. Ela gera uma forte pressão dentro da área científica para buscar resultados, buscar parcerias, o que em nosso caso é complicado, pois a nossa pesquisa continua muito fechada dentro das universidades e institutos governamentais." 


\section{Considerações finais}

Tendo em vista as perguntas e o objetivo que orientaram esse levantamento concluímos que:

os tipos de pesquisa desenvolvidos pelos professores/pesquisadores dos Institutos Federais, conforme os dados são: pesquisa básica e a pesquisa aplicada desenvolvidas de forma integrada. Isso é representado no quadrilátero de quatro câmeras pelo quadrante superior direito chamado, de acordo com Stokes (2005), de Quadrante de Pasteur por desenvolverem a pesquisa básica e a pesquisa aplicada conjuntamente. Os Institutos Federais foram criados para desenvolver pesquisa aplicada, remetendo ao modelo linear de pesquisa, mas entre os professores/pesquisadores selecionados parece prevalecer 0 desenvolvimento da pesquisa básica e da pesquisa aplicada de forma integrada e pelo mesmo pesquisador, o que condiz com o Quadrante de Pasteur.

- considerando os três modelos de relação entre entidades de ensino (neste caso Institutos Federais), empresas e governo no desenvolvimento de pesquisa e inovações, os dados apresentados mostram a relação mais forte entre os Institutos Federais e o governo. Foram mencionadas poucas parcerias entre os Institutos Federais e empresas na condução de pesquisas. Assim, o modelo que melhor se adapta à realidade encontrada nas atividades de pesquisa nos Institutos Federais é o modelo formulado por Sábato e Botana (2011), conhecido como Triângulo de Sábato, em que o governo é o principal incentivador no processo de desenvolvimento científico e tecnológico.

A monitoração das atividades de pesquisa desenvolvidas pelos professores/pesquisadores dos Institutos Federais fornece indicadores necessários não apenas para o aprimoramento da gestão dos Institutos, mas também para que a sociedade seja informada do que está sendo produzido. Contribui, portanto, com o Governo Federal no desenvolvimento de políticas e estratégias que estimulem pesquisas úteis para o próprio Governo, a sociedade e as empresas cumprindo assim o que está estabelecido na Lei 11.892 que criou os Institutos Federais.

\section{Referências}

BRASIL. Presidência da República. Lei no 10.973, de 2 de dezembro de 2004. Dispõe sobre incentivos à inovação e à pesquisa científica e tecnológica no ambiente produtivo e dá outras providências. Diário Oficial da União, Brasília, 3 dez. 2004. Disponível em: $<$ http://www.planalto.gov.br/ccivil 03/ ato2004-

2006/2004/lei/l10.973.htm>. Acesso em: 2 jun. 2015.

BRASIL. Presidência da República. Lei $n^{\circ}$. 11.892, de 29 de dezembro de 2008. Institui a Rede Federal de Educação Profissional, Científica e Tecnológica. Cria os Institutos Federais de Educação, Ciência e Tecnologia, 
e dá outras providências. Diário Oficial da União, Brasília, 30 dez. 2008. Disponível em: <http://www.planalto.gov.br/ccivil 03/ ato20072010/2008/lei/l11892.htm>. Acesso em: 2 jun. 2015.

BUSH, V. Science, the endless frontier. 1945. Disponível em: $<$ http://www.nsf.gov/od/Ipa/nsf50/vbush1945.htm>. Acesso em: 2 jun. 2015.

ETZKOWITZ, H.; LEYDESDORFF, L. The dynamics of innovation: from National Systems and "Mode 2" to a Triple Helix of university-industrygovernment relations. Research Policy, n. 29, p. 109-123, 2000.

FUJINO, A. Avaliação dos impactos da produção científica na produção tecnológica: perspectivas. In: POBLACION, D. A.; WITTER, G. P.; SILVA, J. F. M. da (Org.). Comunicação e produção científica: contexto e avaliação. São Paulo: Angellara, 2006. cap. 14. p. 371-386.

GIBBONS, M. Innovation and the developing system of knowledge production. (2001). Disponivel em: <http://web.archive.org/web/20031227102019/http://edie.cprost.sfu.ca/ summer/papers/Michael.Gibbons.html>. Acesso em: 2 jun. 2015.

LEYDESDORFF, L.; ETZKOWITZ, H. Emergence of a Triple Helix of university-industry-government relations. Science and Public Policy, v. 23, n. 5, p. 279-286, 1996.

LUNDVALL, B.-A. Introduction. In: LUNDVALL, B.-A. (Ed.) National systems of innovation: towards a theory of innovation and interactive learning. London: Printer Publishers, 1992. cap. 1. p. 1-16.

NELSON, R. R.; ROSENBERG, N. Technical innovation and national systems. In: NELSON, R. R. National innovation systems: a comparative study. New York: Oxford University Press, 1993. cap. 1. p. 3-21.

QUERIDO, A. L. de S. Destino das patentes das universidades brasileiras e mapeamento das atividades dos núcleos de inovação tecnológica. 2011. 147f. Tese (Doutorado em Biotecnologia Vegetal) - Centro de Ciências da Saúde, Universidade Federal do Rio de Janeiro, Rio de Janeiro, 2011.

SÁBATO, J. A.; BOTANA, N. La ciencia y la tecnologia en el desarrollo futuro de America Latina. In: SÁBATO, J. A. (Comp.). El pensamiento latino-americano en la problemática ciencia-tecnologia-desarrollodependencia. Buenos Aires: Ediciones Biblioteca Nacional, 2011. cap. 10. p. 215-230.

SCHWARTZMAN, S. A pesquisa científica e o interesse público. Revista Brasileira de Inovação, v. 1, n. 2, p. 361-395, jul/dez. 2002. Disponível em: <http://www.ige.unicamp.br/ojs/index.php/rbi/article/view/248>. Acesso em: 5 jun. 2015.

SCHWARTZMAN, S. Modos de produção do conhecimento científico e tecnológico e as oportunidades para o setor de ensino superior particular. In: ENCONTRO NACIONAL DE PÓS-GRADUAÇÃO NAS IES PARTICULARES, 
6., 2005, Salvador. Anais... Salvador, 2005. Disponível em: $<$ http://www.schwartzman.org.br/simon/2005 salvador.pdf >. Acesso em: 5 jun. 2015.

SCHWARTZMAN, S. Pesquisa universitária e inovação no Brasil. In: AVALIAÇÃO de políticas de ciência, tecnologia e inovação: diálogo entre experiências internacionais e brasileiras: seminário internacional. Brasília: CGEE, 2008. p. 19-43.

STOKES, D. E. O quadrante de Pasteur: a ciência básica e a inovação tecnológica. Campinas: Ed. UNICAMP, 2005. 